\title{
Produtividade de cultivares de roseira sobre diferentes porta-enxertos ou provenientes de estaquia ${ }^{1}$
}

\author{
PATRICIA UNGER CESAR PIZETTA ${ }^{2}$ e KATHIA FERNANDES LOPES PIVETTA ${ }^{2}$
}

\begin{abstract}
RESUMO
Esta pesquisa objetivou avaliar a produtividade de roseiras 'Tineke' e 'Versília', enxertadas sobre diferentes porta-enxertos ou provenientes de estaquia. $\mathrm{O}$ estudo foi conduzido em Andradas (MG), durante o período de março de 2001 a fevereiro de 2002. O delineamento experimental foi inteiramente casualizado com dez tratamentos: os cultivares enxertados sobre nove portaenxertos (Rosa multiflora 'Paulista', $R$. multiflora 'Japones', R. multiflora 'Iowa', R. multiflora 'Kopman's', $R$. indica x multiflora, $R$. indica 'Mayor', $R$. sp. 'Natual Brier', $R$. manetti, $R$. canina 'Inermis') e provenientes de estaquia, com quatro repetições, sendo cada parcela constituída por cinco plantas. Foi anotado o número de hastes florais colhidas por planta por mês. Tendo como parâmetro a produtividade, para a região de Andradas (MG), recomenda-se, como porta-enxertos para o cultivar 'Tineke' preferencialmente $R$. manetti, seguido de $R$. multiflora 'Japones', $R$. multiflora 'Iowa' e R. multiflora 'Kopman's'; para 'Versília', os porta-enxertos R. multiflora 'Paulista', $R$. multiflora 'Japones', $R$. multiflora 'Iowa', $R$. multiflora 'Kopman's', $R$. indica 'Mayor', $R$. sp. 'Natual Brier' e $R$. manetti; não se recomendam os porta-enxertos $R$. canina 'Inermis' e $R$. indica x multiflo$r a$ para ambos os cultivares, nem $R$. indica 'Mayor' para 'Tineke'; podem-se plantar, para ambos os cultivares, mudas provenientes de estaquia.
\end{abstract}

Palavras-chave: produção, enxertia, enraizamento de estacas, rosa.

\begin{abstract}
Productivity of rose cultivars produced by grafting onto different rootstocks or by cutting

The productivity of rose from cultivars Tineke and Versília, grafted on different rootstocks or originated from cutting was compared. The study was conducted in Andradas, Minas Gerais State, from March 2001 to February 2002. The experimental design used was a completely randomized, including ten treatments: Rosa multiflora 'Paulista', $R$. multiflora 'Japones', $R$. multiflora 'Iowa', $R$. multiflora 'Kopman's', $R$. indica $x$ multiflora, $R$. indica 'Mayor', $R$. sp. 'Natual Brier', $R$. manetti, $R$. canina 'Inermis', and cutting. Four replications per treatment were used and each parcel comprised five plants. The number of flower stems harvested per plant was recorded monthly. Based on the productivity of Andradas area (MG), is recommended, as rootstocks for 'Tineke', $R$. manetti, followed by $R$. multiflora 'Japones', $R$. multiflora 'Iowa' and $R$. multiflora 'Kopman's'; for 'Versília', the rootstocks R. multiflora 'Paulista', R. multiflora 'Japones', R. multiflora 'Iowa', $R$. multiflora 'Kopman's', $R$. indica 'Mayor', $R$. sp. 'Natual Brier' and R. manetti; it is not recommended the rootstocks $R$. canina 'Inermis' and $R$. indica x multiflora for both cultivars, also, $R$. indica 'Mayor', for ' Tineke'; it can be planted, for both cultivars, plants originated from cutting.
\end{abstract}

Key words: production, grafting, rooting, rose.

\footnotetext{
${ }^{1}$ Projeto financiado pela FAPESP, processo: 00/01247-0.

2 Departamento de Produção Vegetal, FCAV/UNESP, via de acesso Prof. Paulo Donato Castellane, s/n, 14884-900, Jaboticabal (SP). E-mail: kathia@fcav.unesp.br
} 


\section{INTRODUÇÃO}

A produtividade das roseiras está condicionada a diversos fatores; um dos mais importantes é a escolha de uma boa muda (PIVETTA et al., 1999). As mudas de roseira de corte, no Brasil, são obtidas, na sua maioria, por enxertia de variedades híbridas sobre porta-enxertos de roseiras rústicas provenientes de estaquia. Mudas advindas do enraizamento de estacas herbáceas também têm sido utilizadas por muitos produtores, por ser um método no qual se obtém grande número de plantas com maior economia de espaço, tempo, matrizes e, principalmente, de custo (PIVETTA, 1994).

Embora a enxertia de roseiras seja uma prática comum há anos, pouco se conhece sobre as vantagens desse processo de obtenção de mudas para essa cultura. Possivelmente, a enxertia sempre tenha sido o processo mais utilizado, pois as roseiras silvestres ou variedades com ascendência próxima a elas apresentam facilidade de enraizamento, enquanto as variedades atualmente cultivadas apresentam grande variação na capacidade de diferenciação de raízes (BOETTCHER, 1991).

A escolha do porta-enxerto é uma questão muito polêmica na produção de mudas enxertadas de roseira no Brasil. Há muitos porta-enxertos espalhados pelo Brasil inteiro, mas muitos produtores os utilizam conhecendo-os apenas pelo nome vulgar, ou ainda, fazendo referência à presença ou não de acúleos (PIVETTA, 1999).

Além de não haver controle do porta-enxerto utilizado, pouco se conhece e nunca foram quantificadas, cientificamente, as reais vantagens que $o$ porta-enxerto confere à planta enxertada (PIVETTA, 1999), ao contrário do trabalho realizado com frutíferas, como, por exemplo, citros (POMPEU JÚNIOR, 1991).

Muitos produtores de rosa comentam as vantagens do processo de enxertia e estaquia, com grande variação em função do cultivar, porém, não há estudos no Brasil que indiquem cientificamente as diferenças entre os dois processos (PIVETTA, 1999). Assim, este trabalho tem como objetivo avaliar a produtividade de roseiras, cultivares Tineke e Versília, enxertadas sobre diferentes porta-enxertos ou provenientes de estaquia.

\section{MATERIAL E MÉTODOS}

O experimento foi instalado no Município de Andradas (MG), no Sítio Dallas, de propriedade do Grupo Reijers, localizado à latitude de $22^{\circ} 05^{\prime}$ e longitude de $46^{\circ} 35^{\prime}$ e a uma altitude de 1251 metros acima do nível do mar, com média pluviométrica de $1572 \mathrm{~mm} / \mathrm{ano}$.

As mudas foram plantadas em solo devidamente corrigido, segundo assessoria da propriedade, em casa de vegetação de estrutura metálica, coberta e fechada nas laterais com filme plástico transparente. No interior da casa de vegetação, a temperatura média anual foi de $23^{\circ} \mathrm{C}$ e a umidade relativa média, de $77 \%$.

Foram feitas mudas dos cultivares Tineke e Versília, propagadas por estaquia e enxertia. Os ramos para enxertia e estaquia de ambos os cultivares foram obtidos na propriedade onde foi instalado o experimento, enquanto os porta-enxertos foram provenientes de uma outra propriedade do Grupo Reijers, no Município de Holambra (SP) e da coleção da FCAV/UNESP.

Para as mudas obtidas por estaquia, utilizaram-se estacas semi-herbáceas, provenientes de ramos floríferos, de padrão comercial, cortadas em bisel no ápice e na base, a partir da primeira folha com cinco folíolos, com aproximadamente $8 \mathrm{~cm}$ e duas gemas, sendo retirada a folha basal (PIVETTA, 1994).

Para as mudas obtidas por enxertia, as estacas dos porta-enxertos foram preparadas de ramos semi-herbáceos, com duas gemas e com aproximadamente $8 \mathrm{~cm}$ de comprimento. As estacas dos garfos foram preparadas também de ramos semi-herbáceos, com uma gema e com aproximadamente $4 \mathrm{~cm}$. A enxertia foi do tipo garfagem simples em estacas dos porta-enxertos não enraizados (enxertia de mesa).

As bases das estacas e dos enxertos de mesa foram tratadas com ácido indolbutírico $(2.000 \mathrm{mg} / \mathrm{L})$ via pó e, em seguida, colocadas em um leito contendo casca de arroz carbonizada umedecida. O leito foi coberto com plástico transparente; após trinta dias, as estacas estavam enraizadas e os enxertos de mesa pegos e enraizados, prontos para o plantio em local definitivo.

O plantio foi realizado no mês de março de 2000, após o preparo do terreno no interior da casa de vegetação de $5000 \mathrm{~m}^{2}$, em linha dupla, em canteiros de aproximadamente $1 \mathrm{~m}$ de largura e $50 \mathrm{~m}$ de comprimento. $\mathrm{O}$ espaçamento utilizado foi de $30 \mathrm{~cm}$ entre linhas e entre plantas.

Foram realizados os tratos culturais de acordo com o que se utiliza comercialmente, ou seja, tratamento fi- 
tossanitário, controle de plantas daninhas, irrigação e adubação.

A produção de padrão comercial iniciou-se em março de 2001, sendo, então, anotada mensalmente a produção de cada parcela.

O delineamento experimental estatístico foi inteiramente casualizado com dez tratamentos e quatro repetições, totalizando 40 parcelas. Cada parcela foi constituída por cinco plantas, totalizando 200. Os tratamentos utilizados foram constituídos pelos porta-enxertos: $R$. multiflora 'Paulista', $R$. multiflora 'Japones', $R$. multiflora 'Iowa', $R$. multiflora 'Kopman's', $R$. indica $\mathrm{x}$ multiflora, $R$. indica 'Mayor', $R$. sp. 'Natual Brier', $R$. manetti, R.canina 'Inermis' e mudas provenientes de estaquia.

Cada cultivar, Tineke e Versília, foi estudado separadamente. Os dados coletados foram analisados estatisticamente. Foi realizada a análise de variância e, posteriormente, na comparação das médias dos tratamentos, utilizou-se o teste de Tukey a 5\% de probabilidade (BANZATTO \& KRONKA, 1992). Foi realizada, ainda, a regressão polinomial a fim de se verificar o comportamento dos tratamentos ao longo do ano.

\section{RESULTADOS E DISCUSSÃO}

Para 'Tineke' (Tabela 1), observa-se que o portaenxerto $R$. canina 'Inermis' foi o único que apresentou valores menores de produtividade em todos os meses onde houve efeito significativo do tratamento, embora não tenha diferido estatisticamente de vários outros porta-enxertos.

As maiores produtividades para 'Tineke', de maneira geral, ao longo do ano, foram obtidas na combinação com $R$. manetti, seguido de $R$. multiflora 'Japones' que foram os únicos que se destacaram entre as maiores produtividades em todos os meses estudados; os demais, pelo menos em um mês, não estiveram entre os de maior produtividade, entretanto, esse fato não impede sua utilização. Entre esses tratamentos estão: R. multiflora 'Iowa', R. multiflora 'Kopman's' e mudas provenientes de estaquia (constituindo os dois últimos os melhores tratamentos no mês de setembro). Portanto, para 'Tineke' a grande restrição é com relação ao porta-enxerto $R$. canina 'Inermis', que não deverá ser recomendado para as condições de Andradas (MG), seguido dos porta-enxertos $R$. indica x multiflora, $R$. indica 'Mayor', $R$. multiflora 'Paulista' e $R$. sp. 'Natual Brier'.
Para 'Versília' (Tabela 2), maiores valores de produtividade foram obtidos quando foram utilizados os porta-enxertos $R$. multiflora 'Paulista', $R$. multiflora 'Japones' R. multiflora 'Kopman's' R. indica 'Mayor', $R$. sp. 'Natual Brier' e $R$. manetti.

Os porta-enxertos $R$. indica x multiflora e $R$. canina 'Inermis' possibilitaram as menores médias em três e dois meses, respectivamente, e não diferiram estatisticamente de outros tratamentos.

Verifica-se (Tabelas 1 e 2) que a produtividade das plantas provenientes de estaquia, para ambos os cultivares, esteve entre as melhores, exceto no mês de agosto para 'Tineke' e abril para 'Versilia', indicando que esses cultivares podem ser multiplicados por estaca, diminuindo, conseqüentemente, o custo com a mão-deobra (PIVETTA, 1994), e com o porta-enxerto, já que nessa propriedade os porta-enxertos utilizados são importados da Holanda.

A regressão polinomial mostra que tanto para 'Tineke' (Figura 1) quanto para 'Versília' (Figura 2), de uma maneira geral, a produtividade é menor no inverno, seguindo o padrão da cultura. Somente $R$. indica $x$ multiflora e $R$. indica "Mayor' para 'Tineke' tiveram um ajuste de regressão linear, ou seja, a produtividade foi aumentando ao longo do ano. Esse comportamento, no entanto, parece ser devido ao fato de a combinação desses porta-enxertos com esse cultivar ter demorado mais a atingir o padrão comercial.

\section{CONCLUSÕES}

Com base na produtividade, para a região de Andradas (MG), recomenda-se, como porta-enxertos para o cultivar 'Tineke' preferencialmente $R$. manetti seguido de $R$. multiflora 'Japones', $R$. multiflora 'Iowa' e $R$. multiflora 'Kopman's'; recomenda-se para 'Versília', os porta-enxertos $R$. multiflora 'Paulista', R. multiflora 'Japones', $R$. multiflora 'Iowa', $R$. multiflora 'Kopman's', $R$. indica 'Mayor', $R$. sp. 'Natual Brier' e $R$. manetti; não se recomendam os porta-enxertos $R$. canina 'Inermis' e $R$. indicax multiflora para ambos os cultivares nem $R$. indica 'Mayor' para 'Tineke'; pode-se plantar, para ambos os cultivares, mudas provenientes de estaquia

\section{AGRADECIMENTOS}

Os autores agradecem ao Grupo Reijers, nas pessoas do Sr. Hendrikus Reijers e Sr. Henrique Reijers, pela doação de propágulos dos cultivares e de dois porta-enxertos 


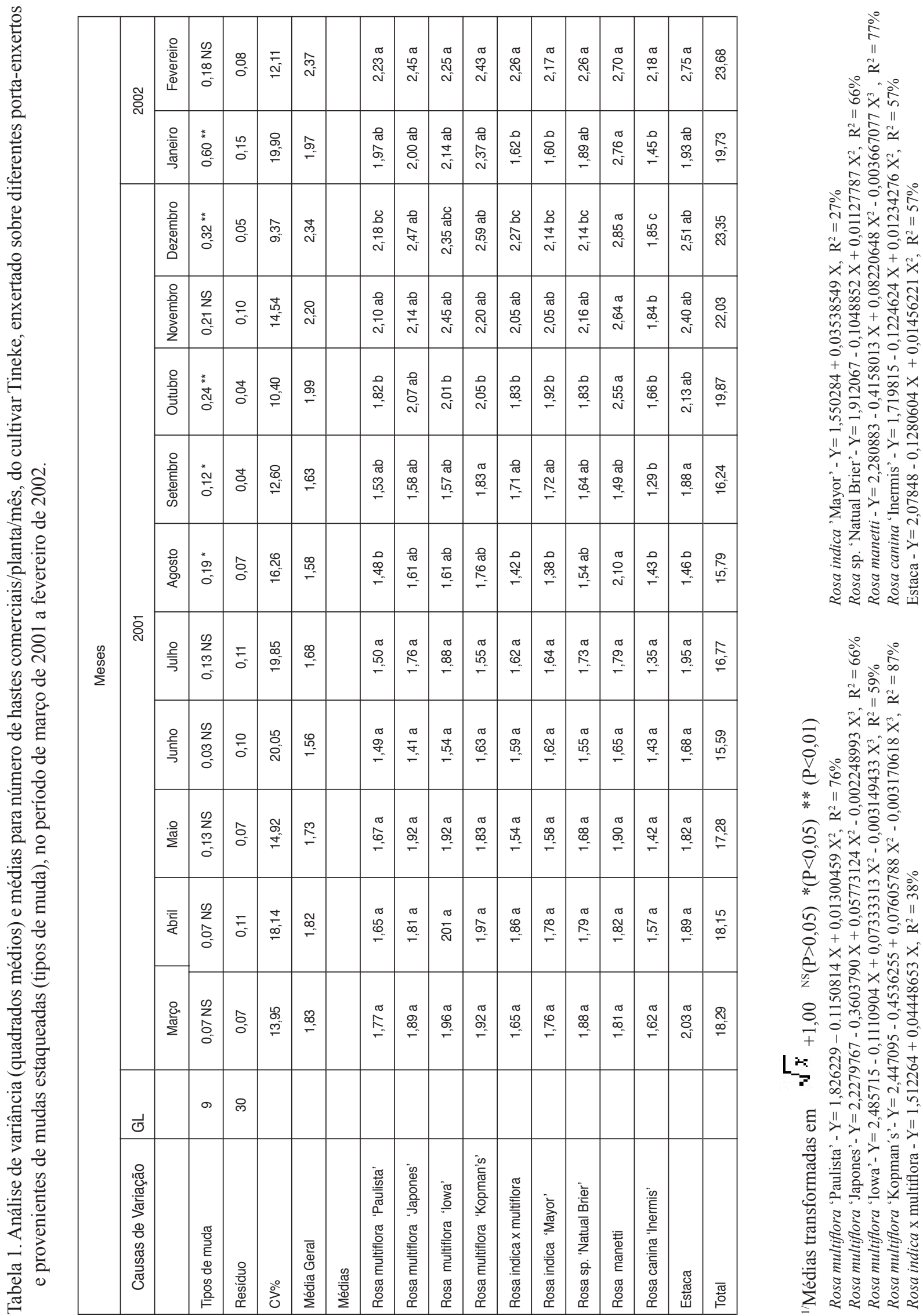




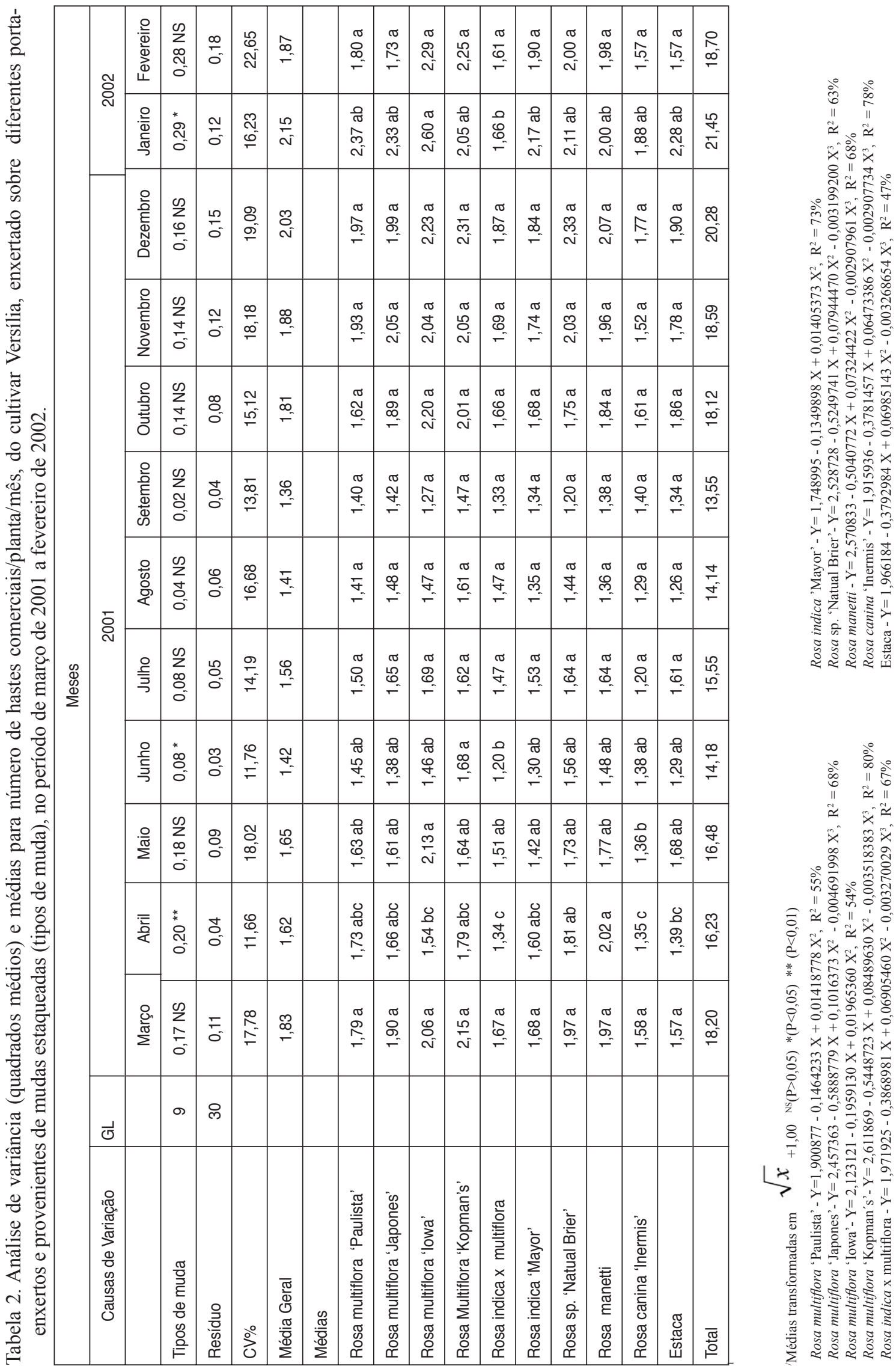



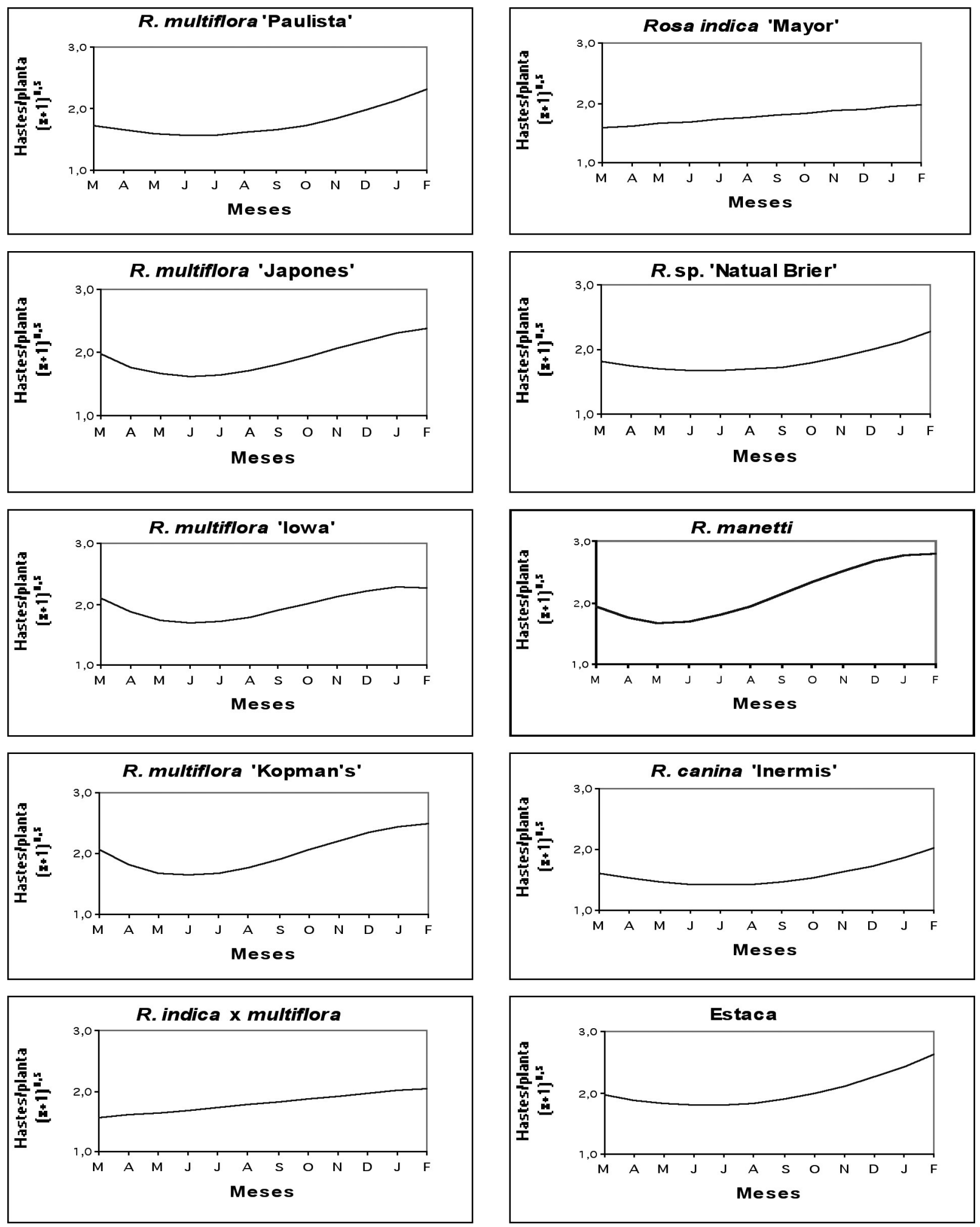

Figura 1. Curvas de regressão entre os meses do ano (março/2001 a fevereiro/ 2002) e a produção de hastes de rosa por planta (número de hastes transformadas em $\sqrt{x}+1,00$ ) para o cultivar Tineke. 

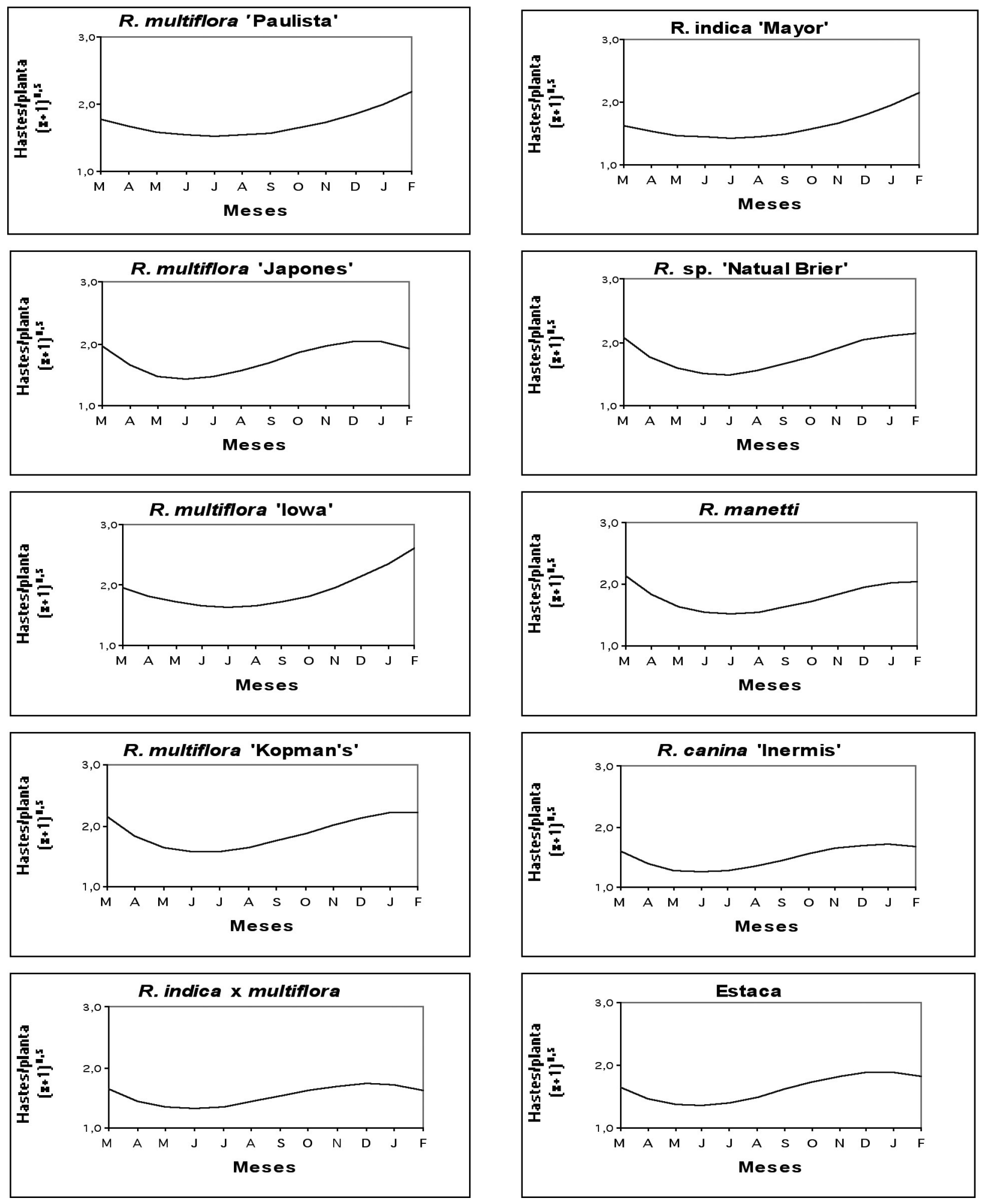

Figura 2. Curvas de regressão entre os meses do ano (março/2001 a fevereiro/ 2002) e a produção de hastes de rosa por planta (número de hastes transformadas em $\sqrt{x}+1,00$ ) para o cultivar Versília. 
e toda a infra-estrutura para o desenvolvimento deste trabalho, e ao Sr. Arno Boettcher pela doação dos demais porta-enxertos que, atualmente, fazem parte da coleção de porta-enxertos de roseira da FCAV/UNESP.

\section{LITERATURA CITADA}

BANZATTO, D. A. \& KRONKA, S. N. Experimentação agrícola. 2 ed. Jaboticabal: FUNEP, 1992. 247p.

BOETTCHER, A. Sítios \& Jardins: rosas. São Paulo: Editora Europa, 1991. 87p.

PIVETTA, K. F. L. Estudos sobre o enraizamento de estacas enfolhadas de roseira (Rosa $\mathbf{s p}$.) 'Red Sucess'. Jaboticabal: Faculdade de Ciências Agrárias e
Veterinárias, UNESP, 1994. 151p. Tese (Doutorado em Agronomia)

PIVETTA, K. F. L. Propagação de roseiras. In. WORKSHOP SOBRE AVANÇOS NA PROPAGAÇÃO DE PLANTAS, 2, 1999, Lavras. Palestras... Lavras, UFLA, 1999. p.41-49.

PIVETTA, K. F. L.; MARTINS, A. B. G.; RUFFINI, F. K. \& LEDRA, L. R. Effects of rooting media, indoldutyric acid and fertilization on the rooting of rose (Rosa sp. 'Dalas') leaf cuttings. Acta Horticulturae, n. 482, p.339-342, 1999.

POMPEU JÚNIOR, J. Porta-enxertos. In: RODRIGUEZ, O. et al. (eds.) Citricultura Brasileira. Campinas: Fundação Cargill, 1991. v.1, p.265-280. 